Journal of Engineering and Applied Sciences 14 (7): 2302-2308, 2019

ISSN: 1816-949X

(C) Medwell Journals, 2019

\title{
Laser Effect on Optical and Structural Properties of CdTe: Al Thin Films Prepared by Pulsed Laser Deposition Technique
}

\author{
Mohammed H. Hwidi, Laith M. Abduljabbar and Amna Emad \\ Dijlah University College, Baghdad, Iraq
}

\begin{abstract}
Thin films of cadmium telluride were deposited using (PLD) technique on a several glass substrates at average temperature range of $300^{\circ} \mathrm{C}$. Different cadmium telluride thin films which has a thickness $(250,350$ and $450 \mathrm{~nm}$ ) were used in this study. Properties of cadmium telluride films such as (optical and structural) were studied. All optical charact eristics of the preparation films were characterized using FTIR spectrophotometer (Shimadzu $8400 \mathrm{~S}$ ) in the range (300-1800) $\mathrm{nm}$. From this measurements, the band gaps energies for different fabricated thickness $(250,350$ and $450 \mathrm{~nm})$ were found to be $2.35,2.565$ and $2.76 \mathrm{eV}$, respectively. The values of the band gaps increased with increasing the thickness of the fabricated films. The alterations of crystalline structure of the prepared thin films were analyzed and studied using XRD procedure. Diffractometer (Shimadzu 6000 made in Japan) was used in the measurements of XRD. The X-ray measurements showed that all CdTe samples are consisting of randomly oriented crystalline parts and have a structure of cubic zinc blend with preferential mode in the [111] direction. The particle size and a lattice constant of the fabricated cadmium telluride films were calculated. The films with higher thickness which has a grain size greater than the other samples.
\end{abstract}

Key words: Laser, thin film, $\mathrm{CdTe}, \mathrm{Al}, \mathrm{XRD}$, telluride films, X-ray

\section{INTRODUCTION}

Cadmium Telluride (CdTe) has optimum direct band gap energy is equal to $1.45 \mathrm{eV}$ at room temperature. High attenuation absorption coefficient $\left(>10^{5} / \mathrm{cm}\right)$ in visible range of solar spectrum and has a high chemical stability. For those reasons $\mathrm{CdTe}$ attracted more attention compared to other materials (Ismail and Gould, 1989; Chopra and Das, 1983; Chopra et al., 2004; Mu et al., 2015).

Therefore, good quality CdTe thin films are considered as an ideal optical material and widely used in various electronic and large area optoelectronic devices like solar cells, X-ray detectors, photo detectors infrared windows, LEDs, lasers etc. (Khairnar et al., 2003; Gunjal et al., 2014; Pandey et al., 2005).

One of the most important applications of CdTe thin film is using it in fabrication of photovoltaic cells. It is an active research area and there is more focus on the produce of low cost, superior stability, efficient thin film solar cells. Nowadays, the semiconductor materials have been widely used in various fields like energy, environmental and biomedical. The conditions of preparation and the deposition technique are very important for cadmium telluride thin films fabrication process. Several methods of deposition is used to prepared the cadmium telluride films such as Pulse Laser Deposition (PLD), electro deposition, sputtering deposition, technique of spray pyrolysis, screen printing, Close-Spaced Sublimation (CSS), Metal Organic Chemical Vapor Deposition (MOCVD), thermal space evaporation etc. ( $\mathrm{Mu}$ et al., 2015; Ding et al., 2013; Rugen-Hankey et al., 2015; Crossay et al., 2012; Liyanage et al., 2015; Salavei et al., 2013; Toma et al., 2014; Ban et al., 2012).

Pulsed Laser Deposition (PLD) has came into view as one of the most common and simple techniques for precipitating $\mathrm{CdTe}$ thin films due to its productivity and very high deposition rate, it can be applied to several materials such as metals, compounds and high quality single crystal materials.

Theory: The crystal construction of the CdTe is due to one of the appearances of a few several studies on photovoltaic technology are being conducted through the application of certain industries such as the production of terrestrial solar cells. With an energy gap of about $(1.5 \mathrm{~V})$ which is almost identical to the energy of the solar spectrum, the photovoltaic cells powered by $\mathrm{CdTe}$ may reach $(15.8 \%)$ of cells with a small area of $1.08 \mathrm{~cm}^{2}$ (Ferekides et al., 1993). 
Technology has been expanded through the industry on a large scale in the field of alternative energy and the evolution of CdTe photovoltaic cells modules has been achieved and the efficiency has reached about $(10 \%)$ and the energy density produced is approximately $\left(100 \mathrm{~W} / \mathrm{m}^{2}\right)$ of photovoltaic cells material (Zweibel, 1995).

Studying correlation of $\mathrm{CdTe}$ films physical properties and their preparation conditions is very necessary for a broader knowledge and a full understanding of that correlation and to improve the nature and the performance of this films for different applications such as vacuum evaporation, divergent sublimation, molecular radiation spacing and the like. This used to prepare the CdTe thin films (So et al., 1987; Bouroushian et al., 1993; El-Kadry et al., 1995; Oliva et al., 1995; Romeo et al., 2000; Mathew, 2000; Sharma et al., 2004).

Vacuum is used with thermal evaporation process most of the time. It provides several possibilities for correcting sedimentation conditions to be studied conditions of preparation-relationship of physical characteristics of CdTe films. The use of this technology provided the preparation of practical parameters such as the thermal grade of the substrate, temperature source and the rate of deposition, quality change and many physical characteristics of cadmium telluride films (Chakrabarti et al., 1999; Cruz and Avillez, 2000; Lee et al., 2003; Lalitha et al., 2004).

To determine the absorption coefficient of CdTe films deposited to measure permeability, $\mathrm{T}$ and Reflectivity, $\mathrm{R}$, during the waveform of the $\mathrm{CdTe}$ absorption edge, through the relationship (Moss et al., 1973).

The use of the spectral absorption method in most cases is the best way to counteract the concentration of molecules and may be considered the only possible method to use (Guo et al., 2003).

Each molecule of CdTe and the nanoparticles has the extinction coefficient will have a complete independence from the size of the molecules within the volumetric system of strong confinement which is consistent with the current theoretical studies of those models (Brus, 1986; Wang and Herron, 1991).

The technique of XRD analysis of the fabricated films that emptied the vacuum shows that the films structure is naturally polycrystalline for the models that were produced at higher temperatures of the substrate (Weller, 1993).

\section{MATERIALS AND METHODS}

Experimental research: The experimental research has been divided into several steps that can be summarized as follows:
Preparation of substrates: Laboratory glass sheet slides are used as a substrate material with diminutions of $75 \times 25 \mathrm{~mm}$ and thickness (1) $\mathrm{mm}$. This interactive materials were cleaned by distilled water and then with alcohol, respectively before being dried with hot water.

Material: $\mathrm{CdTe}$ powder with purity of $99.999 \%$ was used to fabricate the thin films with different thickness. The powder was exposed to pressure of 4 ton to formation a CdTe target with $5 \mathrm{~mm}$ thickness and $30 \mathrm{~mm}$ diameter.

Thin films preparation technique: Pulsed laser deposition technique is used to deposited the CdTe powder on a glass substrates at temperature of $300^{\circ} \mathrm{C}$ using $\mathrm{Nd}: \mathrm{YAG}$ laser (wavelength $0.532 \mu \mathrm{m}$, duration of pulses $10 \mu \mathrm{sec}$, energy density $0.4 \mathrm{~J} / \mathrm{cm}^{2}$ and repetition frequency $6 \mathrm{~Hz}$. Constant speed is used to rotate the target to obtained a uniform ablation as shown in Fig. 1. A laser beam falls on the $\mathrm{CdTe}$ target surface and makes with it at an angle of $45^{\circ}$. Thickness of the fabricated thin films has been measured by weighting method. In this method a digital sensitive balance with accuracy of $\pm 0.0001 \mathrm{~g}$ for weighting the materials which are needed in the fabrication process and for measured the thickness of the prepared cadmium telluride films. The following relation was used to calculate the thickness of the prepared films:

$$
\mathrm{T}=\frac{\mathrm{m}^{*} 10}{\mathrm{~A}^{*} \mathrm{~d}}
$$

Where:

$\mathrm{T}=$ The Thickness $(\mu \mathrm{m})$

$\mathrm{m}=$ Mass of the coating $(\mathrm{mg})$

A $=$ The Area $\left(\mathrm{cm}^{2}\right)$

$\mathrm{d}=$ The density $\left(\mathrm{g} / \mathrm{cm}^{3}\right)$

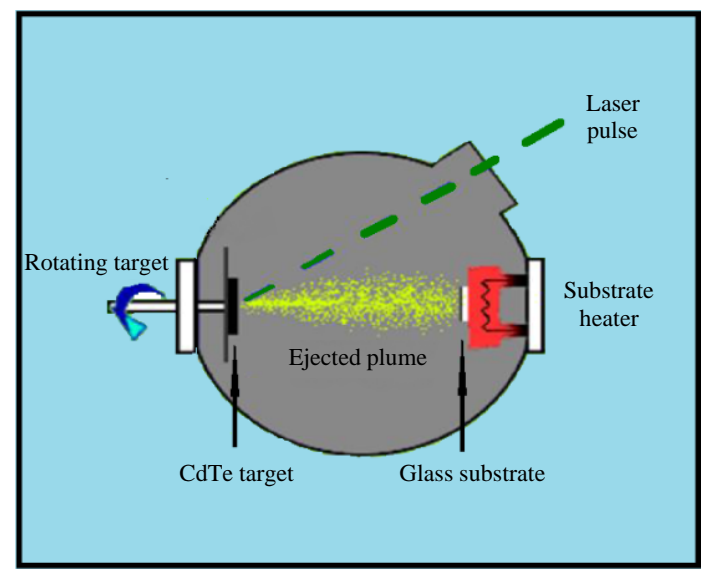

Fig. 1: Pulsed laser deposition technique 
Table 1: The experimental readings and measurements

\begin{tabular}{lccccc}
\hline $\begin{array}{l}\text { Thickness } \\
(\mathrm{nm})\end{array}$ & $2 \theta\left({ }^{\circ}\right)$ & FWHM & $\begin{array}{c}\text { Lattice } \\
\text { constant } \\
(\AA)\end{array}$ & $\begin{array}{c}\text { Grain size (nm) } \\
\text { (calculated) }\end{array}$ & $\begin{array}{c}\text { Grain size (nm) } \\
(\mathrm{SEM})\end{array}$ \\
\hline 250 & 23.74 & 0.0041 & 6.491 & 34.50 & 28.76 \\
350 & 23.66 & 0.0016 & 6.506 & 85.30 & 76.88 \\
450 & 23.62 & 0.0014 & 6.528 & 99.04 & 103.4 \\
\hline
\end{tabular}

Measurements: The XRD technique was used to study the crystalline structure of the prepared cadmium telluride films changes. Analyzed procedure was perform using X-Ray Diffraction (XRD) measurements with diffractometer Shimadzu 6000 which used radiation of $\mathrm{Cu}$ $\mathrm{K} \alpha$ at wavelength $(0.154 \mathrm{~nm})$ and operating at voltage of an accelerating of $40000 \mathrm{~V}$ and $0.03 \mathrm{~A}$ an emission current. The data were obtained in the range of $2 \theta$ from $20-60^{\circ}$. All measurements and tests were conducted at the Nanotechnology Center at the University of Technology Baghdad, Iraq

The deposited CdTe thin films optical transmission spectra were calculated by FTIR Spectrophotometer (Shimadzu $8400 \mathrm{~S}$ ), the optical characteristics where calculated as a function of the wavelength in the range of (300-1800) nm (Table 1).

\section{RESULTS AND DISCUSSION}

In this illustration, three thin films of different thickness were compared to show the coefficient of absorption of each thin film and its relation with wavelength used.

As absorption coefficient increases as the thickness of the cadmium telluride films decreases, the coefficient of absorption of all the films is equal at the wavelength of $900 \mathrm{~nm}$ and then the difference changes again but less than before (Fig. 2).

Figure 3 shows the amount of photon energy for thin film depending on the thickness of it. The photon energy increases as the thickness of the fabricated thin film used is observed to increase rapidly and clearly when the thickness of the film is $250 \mathrm{~nm}$ and less than the thickness of $350 \mathrm{~nm}$ and is clearly reduced at the thickness of $450 \mathrm{~nm}$.

The graph in Fig. 4-7 shown above shows the difference in the size of the gain size by the difference in the thin film's thickness as the gain size increases as the thickness of fabricated films increases and there are a slight difference in the values of gain size between the results of the laboratory research and the results of the theoretical account through the equations. The usual error rate in laboratory instruments and the presence of light sources other than the sources used affect the input of the experiment.

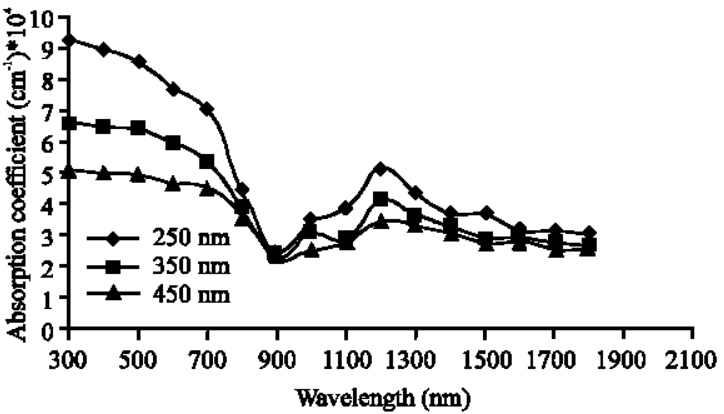

Fig. 2: The relationship between wavelength and absorption coefficient

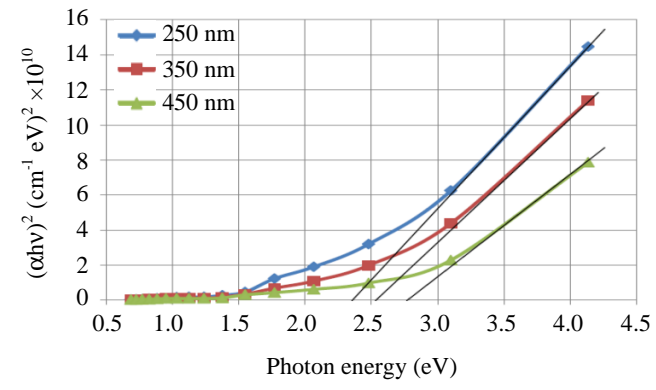

Fig. 3: The curve of photon energy depending on the thickness of slide

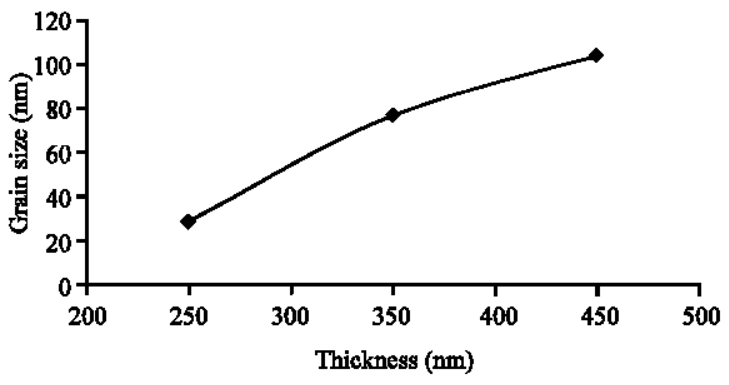

Fig. 4: The grain size at each thickness

The graph in Fig. 8 shows that the lattice constant increases by increasing the thickness of the thin film increasing its value very little (Fig. 8).

In Fig. 9, there are clear differences in energy band gap by the difference in the thin film's thickness used in the experiment. The lowest registered energy band gap at $250 \mathrm{~nm}$ is gradually increasing to the highest energy band gap when user $450 \mathrm{~nm}$.

The transmission value varies from one substance to another and also depends on the thickness of the film used in the same material.

The transmission begins at $300 \mathrm{~nm}$ wavelength and gradually increases in all the thicknesses but increases faster in the thickness of $250 \mathrm{~nm}$ and the lowest increase rate of transmission at a thickness of $450 \mathrm{~nm}$. 


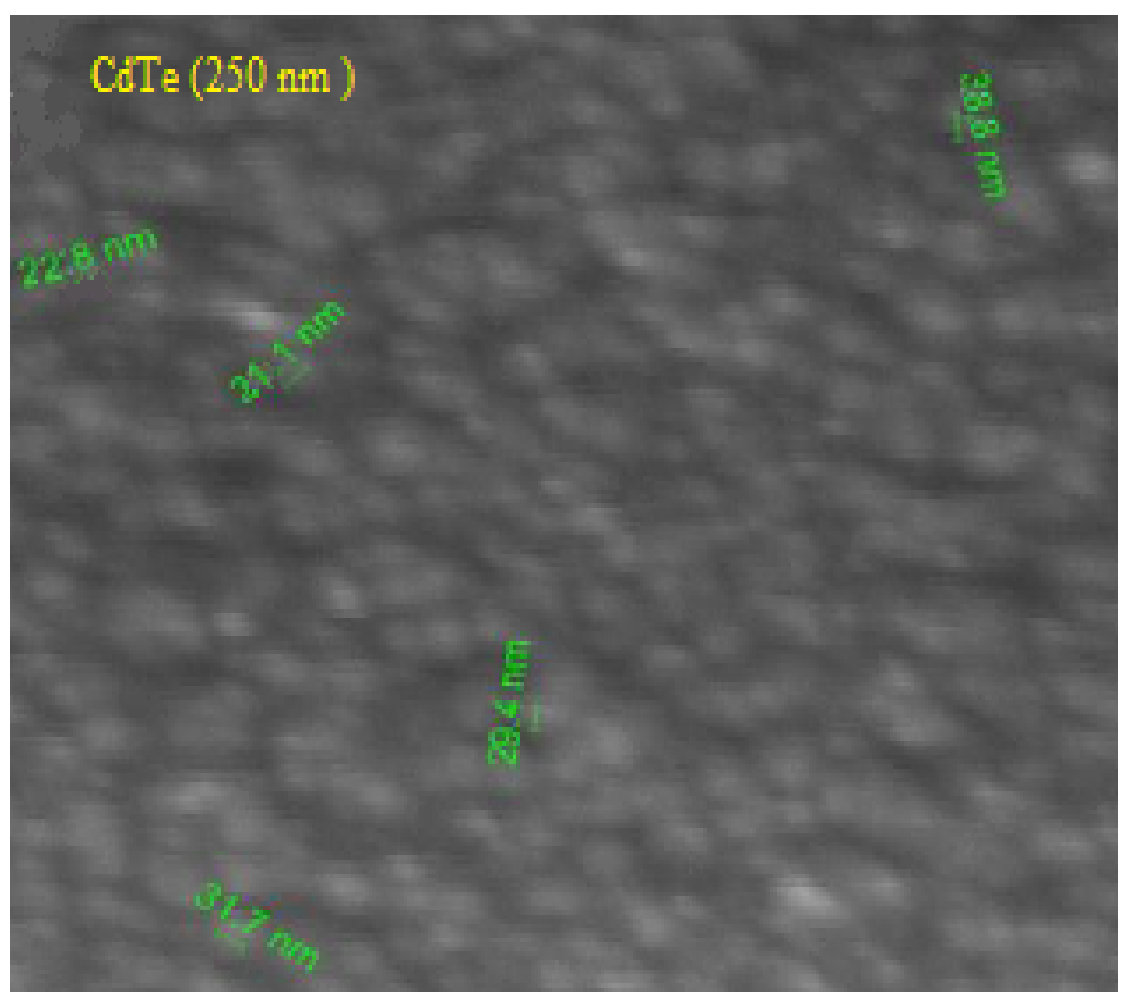

Fig. 5: The grain size at thickness $250 \mathrm{~mm}$

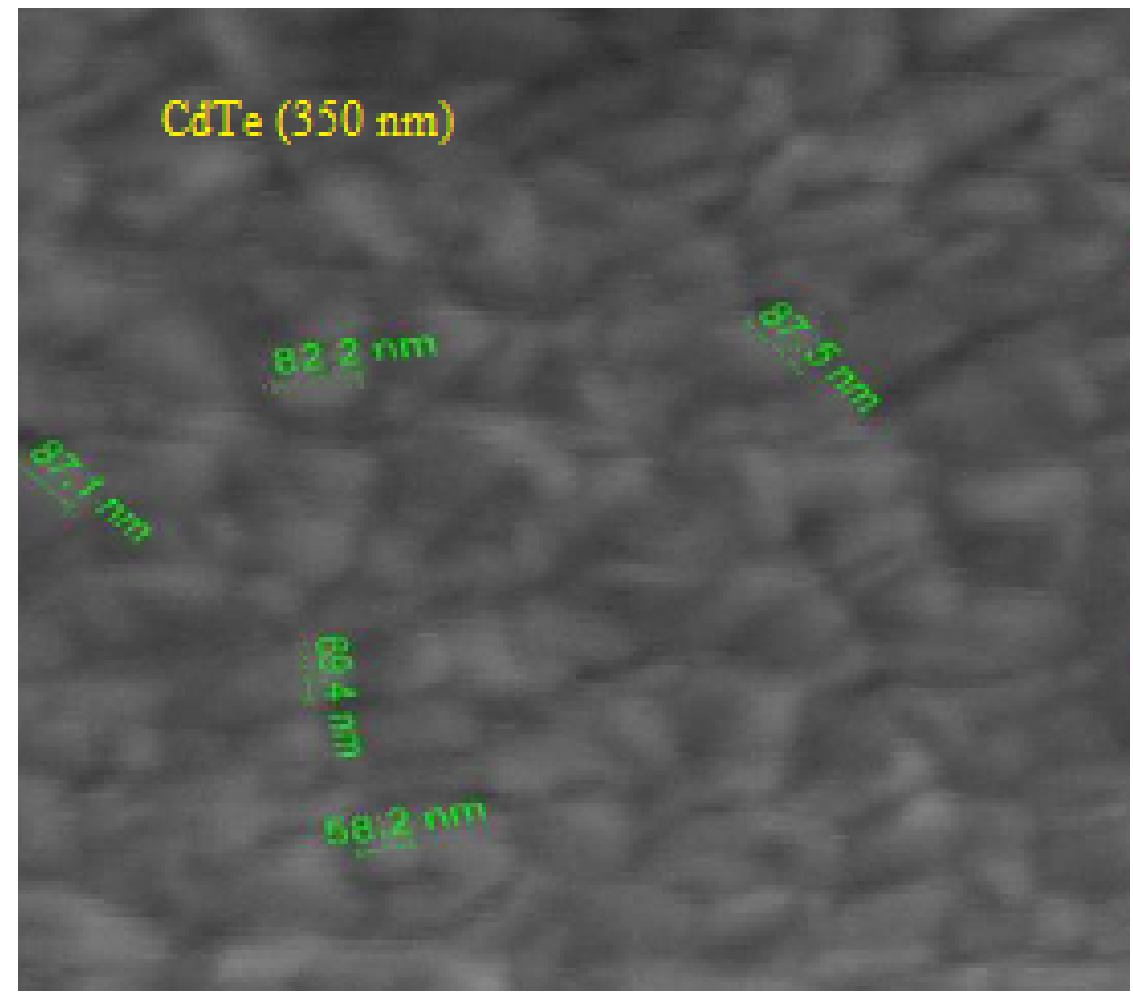

Fig. 6: The grain size at thickness $350 \mathrm{~mm}$ 


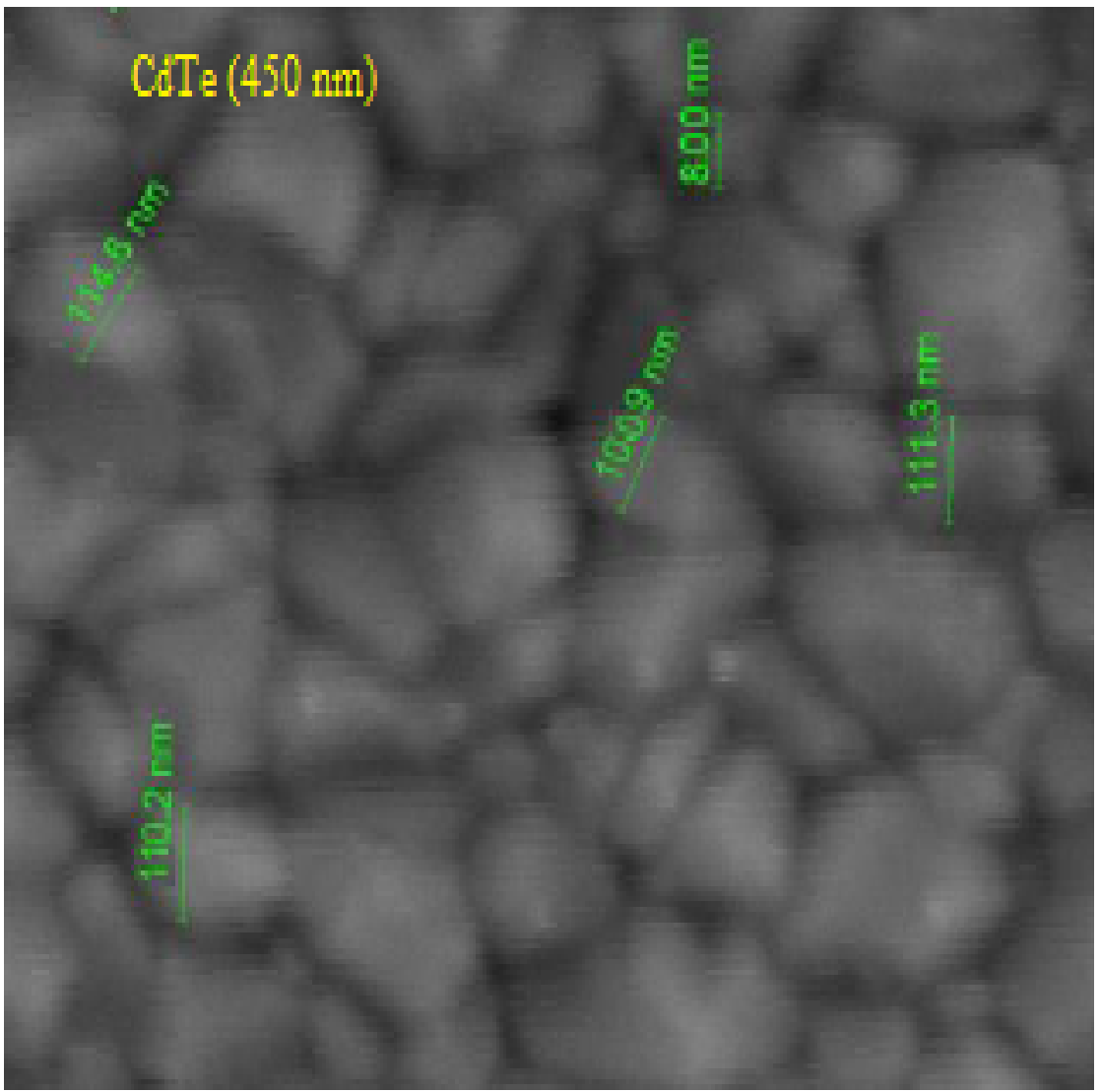

Fig. 7: The grain size at thickness $450 \mathrm{~nm}$

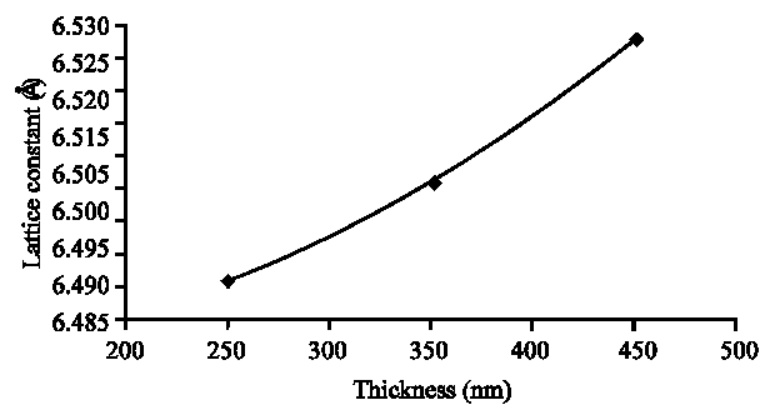

Fig. 8: The lattice constant at each thickness

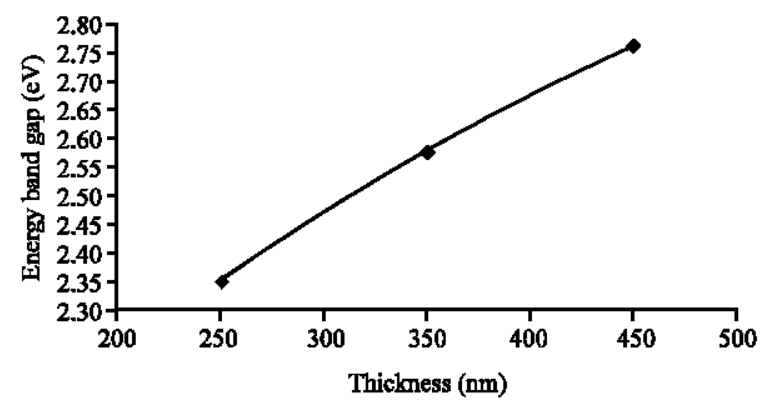

Fig. 9: The energy band gap at each thickness

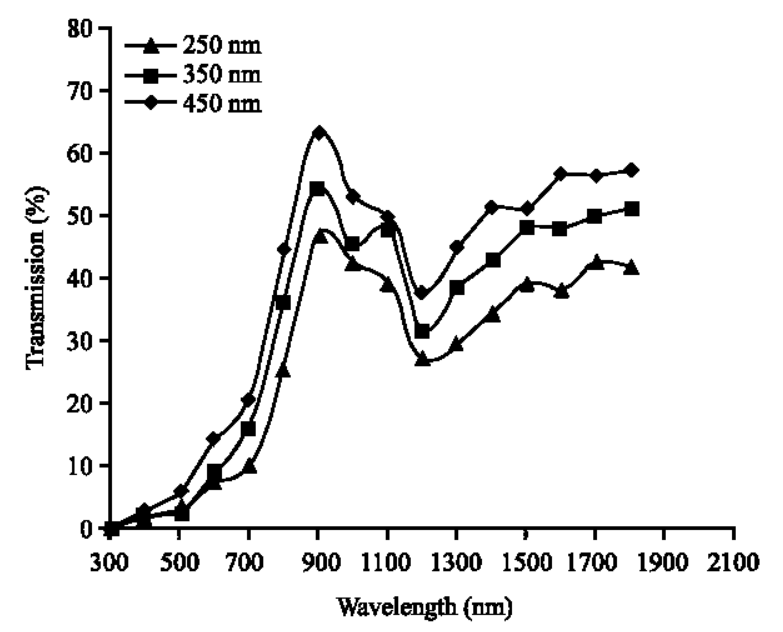

Fig. 10: The variation of transmission for each thickness

The highest value of transmission in all thicknesses when the wavelength reaches $900 \mathrm{~nm}$ and then begins to descend gradually until it reaches the state of stability after it exceeds the wavelength $1200 \mathrm{~nm}$. As shown in Fig. 10 and 11. 


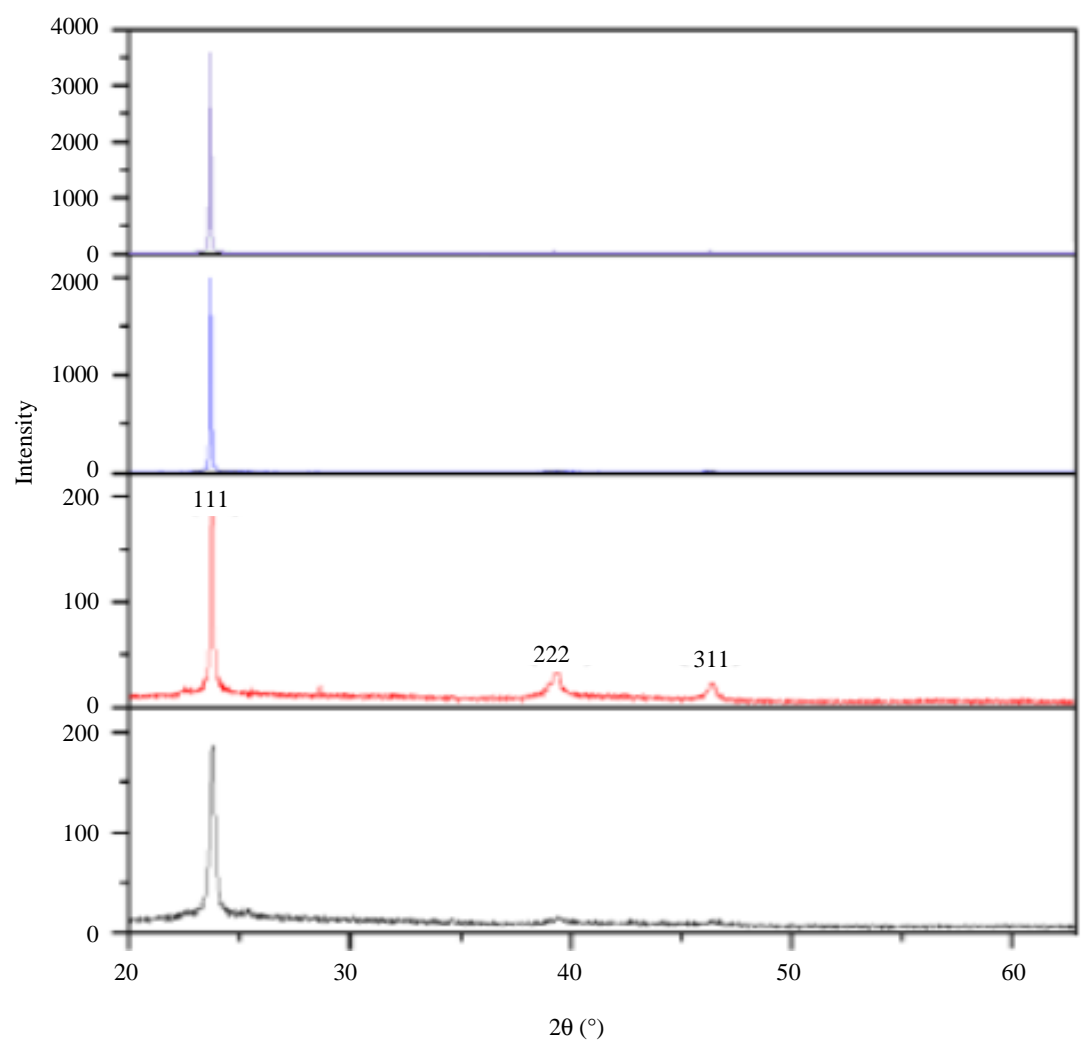

Fig. 11: The spectrum of intensity

\section{CONCLUSION}

The effect of thicknesses (250, 350 and $450 \mathrm{~nm})$ was investigated on the structural and optical properties for $\mathrm{CdTe}$ films evaporated onto glass substrates by Nd: YAG laser (Q switched) with pulse duration $10 \mathrm{~ns}$ and wavelength $0.532 \mu \mathrm{m}$. From X-ray diffraction measurement it is found that all $\mathrm{CdTe}$ films exhibit a polycrystalline structure and have the cubic zinc blend with preferential mode in the [111] direction. Films with higher thickness which has a grain size greater than the other samples. The transmittance decreases and energy band gaps increases with the increase of thickness of the fabricated films which is a proof of improvement of crystallinity.

\section{REFERENCES}

Ban, I., M. Kristl, V. Danc, A. Danc and M. Drofenik, 2012. Preparation of cadmium telluride nanoparticles from aqueous solutions by sonochemical method. Mater. Lett., 67: 56-59.

Bouroushian, M., Z. Loizos, N. Spyrellis and G. Maurin, 1993. Influence of heat treatment on structure and properties of electrodeposited CdSe of $\mathrm{Cd}(\mathrm{Te}, \mathrm{Se})$ semiconducting coatings. Thin Solid Films, 229: 101106.
Brus, L., 1986. Electronic wave functions in semiconductor clusters: Experiment and J. Phys. Chem., 90: 2555-2560.

Chakrabarti, R., S. Ghosh, S. Chaudhuri and A.K. Pal, 1999. Rapid thermal processing for the preparation of CdTe film. J. Phys. D. Appl. Phys., 32: 1258-1262.

Chopra, K.L. P.D. Paulson and V. Dutta, 2004. Thin-film solar cells: An overview. Progr. Photovoltaics: Res. Applic., 12: 69-92.

Chopra, K.L. and S.R. Das, 1983. Thin Film Solar Cells. Plenum Press, New York, USA., ISBN:0-306-41141-5, Pages: 607.

Crossay, A., S. Buecheler, L. Kranz, J. Perrenoud and C.M. Fella et al., 2012. Spray-deposited Al-doped $\mathrm{ZnO}$ transparent contacts for CdTe solar cells. Solar Energy Mater. Solar Cells, 101: 283-288.

Cruz,L.R. andD.R.R. Avillez, 2000. The formation of CdTe thin films by the stacked elemental layer method. Thin Solid Films, 373: 15-18.

Ding, C., Z. Ming, B. Li, L. Feng and J. Wu, 2013. Preparation and characterization of pulsed laser deposited CdTe thin films at higher FTO substrate temperature and in $\mathrm{Ar}+\mathrm{O}_{2}$ atmosphere. Mater. Sci. Eng. B, 178: 801-806. 
El-Kadry, N., A. Ashour and S.A. Mahmoud, 1995. Structural dependence of d.c. electrical properties of physically deposited CdTe thin films. Thin Solid Films, 269: 112-116.

Ferekides, C.S., J. Britt, Y. Ma and L. Killian, 1993. High efficiency $\mathrm{CdTe}$ solar cells by close spaced sublimation. Proceedings of the IEEE 23rd International Conference on Record of the Photovoltaic Specialists, May 10-14, 1993, IEEE, Louisville, Kentucky, USA., pp: 389-393.

Gunjal, S.D., Y.B. Khollam, S.R. Jadkar, T. Shripathi and V.G. Sathe et al., 2014. Spray pyrolysis deposition of p-CdTe films: Structural, optical and electrical properties. Solar Energy, 106: 56-62.

Ismail, B.B. and R.D. Gould, 1989. Structural and electronic properties of evaporated thin films of Cadmium Telluride. Phys. Status Solidi A., 115: 237-245.

Khairnar, U.P., D.S. Bhavsar, R.U. Vaidya and G.P. Bhavsar, 2003. Optical properties of thermally evaporated cadmium telluride thin films. Mater. Chem. Phys., 8: 421-427.

Lalitha, S., R. Sathyamoorthy, S. Senthilarasu, A. Subbarayan and K. Natarajan, 2004. Characterization of CdTe thin Film-dependence of structural and optical properties on temperature and thickness. Solar Energy Mater. Cells, 82: 187-199.

Lee, J.H., D.G. Lim and J.S. Yi, 2003. Electrical and optical properties of CdTe films prepared by vacuum evaporation with close spacing between source and substrate. Solar Energy Mater. Cells, 75: 235-242.

Li, J.J., Y.A. Wang, W. Guo, J.C. Keay and T.D. Mishima et al., 2003. Large-scale synthesis of nearly monodisperse $\mathrm{CdSe} / \mathrm{CdS}$ core/shell nanocrystals using air-stable reagents via successive ion layer adsorption and reaction. J. Am. Chem. Soc., 125: 12567-12575.

Liyanage, W.P., J.S. Wilson, E.C. Kinzel, B.K. Durant and M. Nath, 2015. Fabrication of CdTe nanorod arrays over large area through patterned electrodeposition for efficient solar energy conversion. Solar Energy Mater. Cells, 133: 260-267.

Mathew, X., 2000. Does the band gap calculated from the photocurrent of Schottky devices lead to erroneous results? Analysis for CdTe. J. Phys. D. Appl. Phys., 33: $1565-1571$.

Moss, T.S., G.J. Burrell and B. Ellis, 1973. Semiconductor Opto-Electronics. Butterworth Inc, Houston, Texas, USA., ISBN:9780408703260, Pages: 441.
Mu, Y., X. Zhou, H. Yao, S. Su and P. Lv et al., 2015. Fabrication of $\mathrm{CdTe} / \mathrm{NiTe}$ films on Ni foils by Radiofrequency magnetron sputtering method. J. Alloys Compd., 629: 305-309.

Oliva, A.I., E. Anguiano, M. Aguilar, R. Castro-Rodriguez and J.L. Pena, 1995. Cadmium telluride thin films doped with indium: A morphological study. J. Mater. Sci. Mater. Electron., 6: 154-160.

Pandey, S.K., U. Tiwari, R. Raman, C. Prakash and V. Krishna et al., 2005. Growth of cubic and hexagonal $\mathrm{CdTe}$ thin films by pulsed laser deposition. Thin Solid Films, 473: 5457.

Romeo, N., A. Bosio, R. Tedeschi and V. Canevari, 2000. Growth of polycrystalline CdS and CdTe thin layers for high efficiency thin film solar cells. Mater. Chem. Phys., 66: 201-206.

Rugen-Hankey, S.L., A.J. Clayton, V. Barrioz, G. Kartopu and S.J.C. Irvine et al., 2015. Improvement to thin film CdTe solar cells with controlled back surface oxidation. Solar Energy Mater. Solar Cells, 136: 213217.

Salavei, A., I. Rimmaudo, F. Piccinelli and A. Romeo, 2013. Influence of $\mathrm{CdTe}$ thickness on structural and electrical properties of $\mathrm{CdTe} / \mathrm{CdS}$ solar cells. Thin Solid Films, 535: 257-260.

Sharma, R.K., G. Singh and A.C. Rastogi, 2004. Pulsed electrodeposition of CdTe thin films: Effect of pulse parameters over structure, stoichiometry and optical absorption. Solar Energy Mater. Solar Cells, 82: 201 215.

So, S.M., W. Hwang, P.V. Meyers and C.H. Liu, 1987. Defect levels in electrodeposited n-type CdTe thin films. J. Appl. Phys., 61: 2234-2243.

Toma, O., L. Ion, M. Girtan and S. Antohe, 2014. Optical, morphological and electrical studies of thermally vacuum evaporated $\mathrm{CdTe}$ thin films for photovoltaic applications. Solar Energy, 108: 51-60.

Wang, Y. and N. Herron, 1991. Nanometer-sized semiconductor clusters: Materials synthesis, quantum size effects and photophysical properties. J. Phys. Chem., 95: 525-532.

Weller, H., 1993. Quantized semiconductor particles: A novel state of matter for materials science. Adv. Mater., 5: 88-95.

Zweibel, K., 1995. Thin films: Past, present, future. Prog. Photovoltaics Res. Appl., 3: 279-293. 